\title{
Zn(II)-curc targets p53 in thyroid cancer cells
}

\author{
ALESSIA GARUFI $^{1,2}$, VALERIO D'ORAZI ${ }^{3}$, ALESSANDRA CRISPINI $^{4}$ and GABRIELLA D'ORAZI ${ }^{1,2}$ \\ ${ }^{1}$ Department of Experimental Oncology, Regina Elena National Cancer Institute, Rome; ${ }^{2}$ Department of Medical, \\ Oral and Biotechnological Sciences, University 'G. d'Annunzio', Chieti; ${ }^{3}$ Department of Surgical Sciences, \\ Sapienza University, Rome; ${ }^{4}$ Department of Chemistry and Technologic Chemistry, University of Calabria, Cosenza, Italy
}

Received May 25, 2015; Accepted July 13, 2015

DOI: 10.3892/ijo.2015.3125

\begin{abstract}
TP53 mutation is a common event in many cancers, including thyroid carcinoma. Defective p53 activity promotes cancer resistance to therapies and a more malignant phenotype, acquiring oncogenic functions. Rescuing the function of mutant p53 (mutp53) protein is an attractive anticancer therapeutic strategy. $\mathrm{Zn}$ (II)-curc is a novel small molecule that has been shown to target mutp53 protein in several cancer cells, but its effect in thyroid cancer cells remains unclear. Here, we investigated whether $\mathrm{Zn}$ (II)-curc could affect p53 in thyroid cancer cells with both p53 mutation (R273H) and wild-type p53. Zn(II)-curc induced mutp53H273 downregulation and reactivation of wild-type functions, such as binding to canonical target promoters and target gene transactivation. This latter effect was similar to that induced by PRIMA-1. In addition, $\mathrm{Zn}$ (II)-curc triggered p53 target gene expression in wild-type p53-carrying cells. In combination treatments, $\mathrm{Zn}$ (II)-curc enhanced the antitumor activity of chemotherapeutic drugs, in both mutant and wild-type-carrying cancer cells. Taken together, our data indicate that $\mathrm{Zn}$ (II)-curc promotes the reactivation of p53 in thyroid cancer cells, providing in vitro evidence for a potential therapeutic approach in thyroid cancers.
\end{abstract}

\section{Introduction}

Thyroid carcinoma is a common malignant tumor of endocrine glands and the most common cancer in head and neck; it exhibits the full range of malignant behaviors from the relatively indolent occult differentiated type to uniformly aggressive and lethal anaplastic variety (1). Thyroid tumor formation is associated with many genetic and environmental causes. In addition, numerous factors are also required to promote thyroid cancer progression (2). Although well differ-

Correspondence to: Dr Gabriella D'Orazi, Department of Medical, Oral and Biotechnological Sciences, University 'G. d'Annunzio', I-66013 Chieti, Italy

E-mail: gdorazi@unich.it

Key words: mutant p53, p53 reactivation, zinc compound, thyroid cancer, chemosensitivity entiated thyroid carcinomas are efficiently cured by surgery and radioiodine, undifferentiated thyroid carcinomas (10-20\% of total) are very resistant to chemotherapy (3-6). Therefore, novel and more efficacious therapies are urgently needed for these tumors.

TP53 is the most commonly mutated gene in human cancers, thus, $>50 \%$ of all human cancer cases carry mutations within the TP53 locus (7). Unlike other oncosuppressors, p53 gene always carries a single monoallelic missense mutation that mainly resides in its DNA-binding domain (DBD) that abolishes its ability to bind to specific DNA sequences recognized by wild-type (wt) p53 (8). Loss of wtp53 activity leads to inhibition of its oncosuppressor function promoting resistance to chemo- and radio-therapies (9). Mutant p53 (mutp53) proteins frequently exhibit a dominant-negative activity over the wtp53 allele by interacting with wtp53 and reducing cellular concentration of functional wtp53 (10). Recent studies have shown that mutations of the TP53 gene can confer oncogenic functions (gain of function, GOF) that are exerted in a variety of ways, ranging from enhanced proliferation in culture, increased tumorigenicity in vivo, and enhanced resistance to a variety of commonly used anticancer drugs (11-13). Indeed, tumors emerging from mutant-p53 knock-in mice display aggressive and metastatic traits that are never detected in tumors developing in a p53-deficient mice $(14,15)$. Mutations of p53 are detectable in $15 \%$ of malignant thyroid tumors and are associated with the progression from differentiated to anaplastic carcinoma (16). Thus, p53 mutations have an effect on infiltration, lymphatic metastasis and prognosis of thyroid carcinoma (17).

Several efforts are in progress to discover efficient agents, such as small molecules, that target mutp53 in cancers, including thyroid cancers (18), both to abolish mutp53 function or to reactivate the wtp53 counterparts (19). The final aim is to restore p53 oncosuppressor functions and improve tumor response to therapies. We recently showed that $\mathrm{Zn}$ (II) supplementation in several cancer cells carrying mutp53, including colon, breast, and glioblastoma, restores a folded conformation from mutp53 misfolding, rescuing wtp53/DNA-binding and transactivation (20-22). The rationale to use $\mathrm{Zn}$ (II) comes from the fact that p53 protein includes one zinc ion $\left(\mathrm{Zn}^{2+}\right)$ as an important cofactor for the proper protein folding to efficiently bind the DNA of sequence-specific target genes (23). Interestingly, mutp53 proteins are prone to the loss of the $\mathrm{Zn}$ (II) bound to the DNA binding domain (DBD) with the 
consequence of protein unfolding and aggregation with loss of wild-type activity (24), therefore, zinc supplementation has been shown to be a useful strategy to target mutp53 proteins $(25,26)$.

In this study we asked whether zinc supplementation might affect p53 in two different thyroid cancer cell lines, one carrying p53-R273H (Arg to His at codon 273) mutation (FTC-133) that is one of the p53 mutation responsible of resistance to antitumor drugs (11) and another with wtp53 (WRO). We used a novel curcumin-based zinc compound [Zn(II)-curc] that we previously showed to reactivate mutp53 proteins (27) and to induce mutp53 degradation through autophagy (28). Here, we found that $\mathrm{Zn}$ (II)-curc reduced mutp53 protein levels in FTC-133 cells, reactivating the wtp53 functions with increased response to therapies. Of note, $\mathrm{Zn}$ (II)-curc also inducted wtp53 transcriptional activity in wtp53-carrying cell line. These findings suggest that $\mathrm{Zn}$ (II)-curc may be a useful compound in therapeutic regimens of thyroid cancers, carrying both mutant and wtp53, that will be worth further testing for translational purpose in clinical practice.

\section{Materials and methods}

Cell culture and reagents. Human thyroid FTC-133 cell line was obtained from European Collection of Cell Cultures (ECACC, Salisbury, UK). It derives from a lymph node metastasis of a follicular thyroid carcinoma and carries p53R273H mutation and EGFR overexpression. FTC-133 and WRO (wtp53) (ECACC) cancer cell lines were routinely maintained in DMEM-Ham's-F12 (Life Technology-Invitrogen), supplemented with $10 \%$ heat-inactivated fetal bovine serum (FBS), $100 \mathrm{U} / \mathrm{ml}$ penicillin, $100 \mu \mathrm{g} / \mathrm{ml}$ streptomycin (Life Technology-Invitrogen), and $2 \mathrm{mmol} / \mathrm{l} \mathrm{L}$-glutamine in a humidified atmosphere with $5 \% \mathrm{CO}_{2}$ and $95 \%$ air at $37^{\circ} \mathrm{C}$.

For treatments the following reagents were used: $\mathrm{Zn}(\mathrm{II})$ curc $(29,30)$ dissolved in DMSO was added to the culture medium to a final concentration ranging between 40 and $120 \mu \mathrm{M}$; chemotherapeutic agent adriamycin (ADR) (Sigma), dissolved in PBS was added to the culture medium to a final concentration ranging between 0.2 and $2 \mu \mathrm{g} / \mathrm{ml}$ and cisplatin (Teva Pharma-Italia, Italy) was added to the culture medium to a final concentration ranging between 0.5 and $5 \mu \mathrm{g} / \mathrm{ml}$; PRIMA-1 (p53 reactivation and induction of massive apoptosis-1) (Sigma) was added to the culture medium to a final concentration $10 \mu \mathrm{M}$ for $24 \mathrm{~h}$. PBS and DMSO solvents were used as control.

Viability assay. Exponentially proliferating cells were plated at subconfluence in triplicate in 60-mm Petri dishes and $24 \mathrm{~h}$ later treated with $\mathrm{Zn}(\mathrm{II})$-curc alone or combination with chemotherapeutic agents for $24 \mathrm{~h}$. Both floating and adherent cells were collected and cell viability was determined by trypan blue exclusion by direct counting with a hemocytometer, as reported (31). The percentage of cell viability, as blue/total cells, was assayed by scoring 200 cells per well three times.

Western blot analysis. Total cell extracts were prepared by incubation at $4^{\circ} \mathrm{C}$ for $30 \mathrm{~min}$ in lysis buffer $[50 \mathrm{mmol} / \mathrm{l} \mathrm{Tris}-\mathrm{HCl}$, $\mathrm{pH} 7.5,150 \mathrm{mmol} / 1 \mathrm{NaCl}, 150 \mathrm{mmol} / \mathrm{l} \mathrm{KCl}, 1 \mathrm{mmol} / \mathrm{l}$ dithioth- reitol, $5 \mathrm{mmol} / 1$ EDTA, pH 8.0, $1 \%$ Nonidet P-40] plus a mix of protease and phosphatase inhibitors (Roche Diagnostic). Cell lysates were spun at $15,000 \mathrm{~g}$ for $15 \mathrm{~min}$ to remove debris and collect the supernatant (total cell extracts). Protein concentration was then determined using BCA Protein Assay kit (Bio-Rad). Equal amount of total cell extracts were resolved according to molecular weight on 10-18\% SDS-polyacrylamide gel electrophoresis. Proteins were transferred to a polyvinylidene difluoride membrane (PVDF, Millipore). Unspecific binding sites were blocked by incubating membranes for $1 \mathrm{~h}$ in $0.05 \%$ Tween-20 (v/v in TBS) supplemented with 5\% non-fat powdered milk or bovine serum albumin, followed by overnight incubation with the following primary antibodies: LC3B (Sigma-Aldrich), rabbit polyclonal anti-p53 (FL393), rabbit polyclonal anti-p21 and anti-p62 (Santa Cruz Biotechnology, Dallas, TX, USA), (p)-Akt (Ser473), tot-Akt (Cell Signaling Technologies, Danvers, MA, USA), polyclonal anti-EGFR antibodies (Santa Cruz Biotechnology, Santa Cruz, CA, USA) and purified mouse anti-phospho-histone H2AX (Ser139, $\gamma \mathrm{H} 2 \mathrm{AX}$ ) (Millipore, clone JBW301). Equal lane loading was monitored by probing membranes with antibodies specific for $\beta$-actin (Calbiochem, San Diego, CA, USA) or tubulin (Immunological Sciences, Rome, Italy). Primary antibodies were detected with appropriate horseradish peroxidaselabeled secondary antibodies (Bio-Rad, Hercules, CA, USA). Enzymatic signals were visualized using chemiluminescence (ECL Detection system, GE Healthcare, Milan, Italy).

RNA extraction and semi-quantitative RT-PCR. Cells were harvested in TRIzol reagent (Invitrogen) and total RNA was isolated following the manufacturer's instructions. The first strand cDNA was synthesized from $2 \mu \mathrm{g}$ of total RNA with MuLV reverse transcriptase kit (Applied Biosystems, Foster City, CA, USA). Semi-quantitative RT-PCR was performed essentially as previously described (20). cDNA was synthesized from $2 \mu \mathrm{g}$ of total RNA with MuLV reverse transcriptase kit (Applied Biosystems). Semi-quantitative reverse-transcribed (RT)-PCR was carried out by using Hot-Master Taq polymerase (Eppendorf S.r.l., Milan, Italy) with $2 \mu \mathrm{l}$ cDNA reaction and gene-specific oligonucleotides under conditions of linear amplification. PCR products were resolved on $2 \%$ agarose gel and visualized with ethidium bromide staining using UV light. The 28S mRNA sequence was used as control for efficiency of RNA extraction and transcription. Densitometric analysis was applied to quantify mRNA levels compared to control gene expression.

Chromatin immunoprecipitation (ChIP) assay. ChIP analysis was carried out essentially as previously described (20). Briefly, cells were crosslinked with $1 \%$ formaldehyde for $10 \mathrm{~min}$ at room temperature and then inactivated by the addition of $125 \mathrm{mM}$ glycine. Chromatin extracts containing DNA fragments with an average size of $500 \mathrm{bp}$ were incubated overnight at $4^{\circ} \mathrm{C}$ with milk, shaking using polyclonal anti-p53 antibody (FL393, Santa Cruz Biotechnology). Before use, protein G (Pierce) was blocked with $1 \mu \mathrm{g} / \mu \mathrm{l}$ sheared herring sperm DNA and $1 \mu \mathrm{g} / \mu \mathrm{l}$ BSA for $3 \mathrm{~h}$ at $4^{\circ} \mathrm{C}$ and then incubated with chromatin and antibody for $2 \mathrm{~h}$ at $4^{\circ} \mathrm{C}$. PCR was performed with Hot-Master Taq (Eppendorf) using $2 \mu \mathrm{l}$ of immunoprecipitated DNA and promoter-specific primers spanning p53 binding sites. 


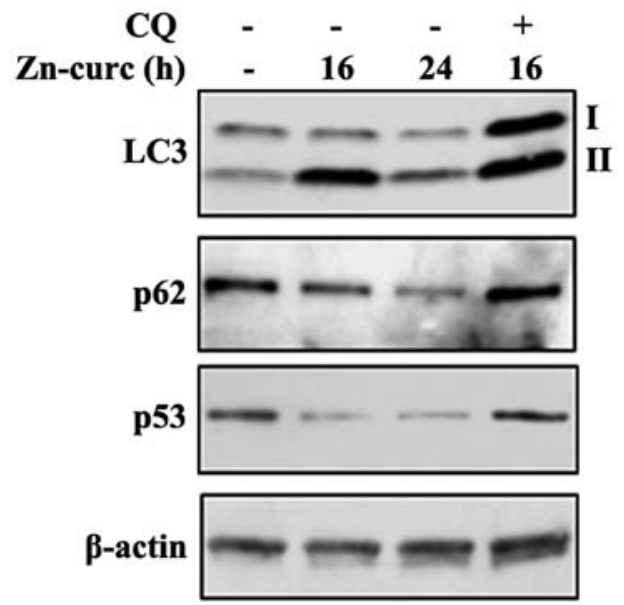

Figure $1 . \mathrm{Zn}$ (II)-curc induces autophagy and mutp53 downregulation in FTC-133 cells. Subconfluent FTC-133 cells were treated with Zn(II)-curc $(80 \mu \mathrm{M})$ for 16 and $24 \mathrm{~h}$ alone or in combination with cloroquine (CQ) $(25 \mu \mathrm{M})$ for $16 \mathrm{~h}$. Equal amount of total cell lysates were subjected to immunoblot analysis to detect the indicated proteins. Anti- $\beta$-actin was used as protein loading control. One representative blot from three independent experiments, all revealing similar results, is shown.

Immunoprecipitation with non-specific immunoglobulins (IgG, Santa Cruz Biotechnology) was performed as negative controls. PCR products were resolved on $2 \%$ agarose gel and visualized by ethidium bromide staining using UV light.

Statistical analysis. Each experiment, unless otherwise specified, was performed at least three times, and data are presented as the mean \pm SD. Statistical significance was determined using Student's t-test and a P-value of $\leq 0.05$ was considered statistically significant.

\section{Results}

Zn(II)-curc induces autophagy and mutp53 downregulation in FTC-133 cells. We previously reported that $\mathrm{Zn}$ (II)-curc induces mutp53 degradation through autophagy in breast cancer cells (28). As defects in autophagy may be found in cancer, we evaluated whether Zn-curc could induce autophagy in FTC-133 thyroid cancer cells. We evaluated the expression of microtubule-associated protein light chain 3 (LC3) protein that, after conversion from LC3-I to its autophagosome membrane-associated lipidated form LC3-II, is considered a cellular readout of autophagy, and the expression levels of p62, a bona fide autophagic substrate (32). As shown in Fig. 1, $\mathrm{Zn}$ (II)-curc increased LC3-II expression and reduced p62 levels; parallel to induction of autophagy, $\mathrm{Zn}$ (II)-curc triggered mutp53 downregulation in FTC-133 cells (Fig. 1). The use of chemical inhibitors of autophagic/lysosomal degradation cloroquine (CQ) (32) prevented Zn(II)-curc-induced mutp53 degradation (Fig. 1). These findings indicate that $\mathrm{Zn}$ (II)-curc induced mutp53 degradation in FTC-133 cells, carrying p52R273H mutation, likely through autophagy.

$\mathrm{Zn}(\mathrm{II})$-curc restores wtp53/DNA binding and target gene transcription in FTC-133 thyroid cancer cells. We then evaluated whether $\mathrm{Zn}$ (II)-curc was promoting reactivation of wtp53 function in FTC-133 cells. We first performed p53/DNA binding by ChIP analyses and found that $\mathrm{Zn}$ (II)-curc treatment indeed restored the wtp53 binding to several specific target promoters, including Puma, p53AIP1, MDM2, and $p 21$, while abolished the p53 binding to the mutant p53 target promoter MDRl (multi-drug resistance 1) (Fig. 2A). As a consequence, the expression of the canonical wtp53 target genes was evaluated by reverse transcription polymerase chain reaction (RT-PCR) analyses. FTC-133 cells were exposed to increasing doses of $\mathrm{Zn}$-curc (40, 80 and $120 \mu \mathrm{M}$ for $24 \mathrm{~h}$ ) that
$\mathbf{A}$

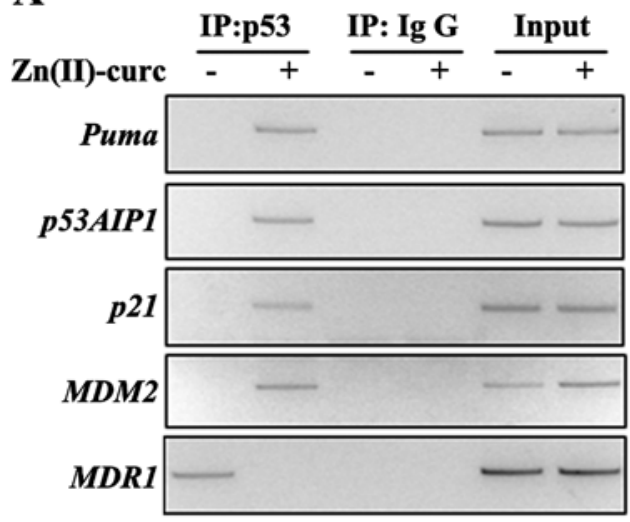

B

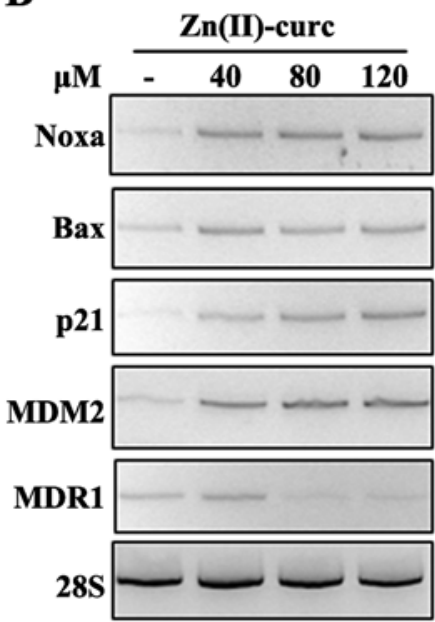

Figure 2. Zn(II)-curc restores wtp53/DNA binding and target gene transcription in FTC-133 thyroid cancer cells. (A) FTC-133 cells (4x106) were plated in $150-\mathrm{mm}$ dish and the day after treated with $\mathrm{Zn}(\mathrm{II})$-curc $(80 \mu \mathrm{M})$ for $16 \mathrm{~h}$ before assayed for chromatin immunoprecipitation (ChIP) analysis with anti-p53 (FL393) antibody. PCR analyses were performed on the immunoprecipitated DNA samples using primers specific for wtp53 (Puma, p53AIP1, p21, MDM2) and mutp53 (MDR1) target gene promoters. A sample representing linear amplification of the total chromatin (input) was included as control. Additional controls included immunoprecipitation performed with non-specific immunoglobulins (IgG). (B) Semi-quantitative RT-PCR analyses of p53 target genes in FTC-133 cells treated with Zn(II)-curc (40, 80 and $120 \mu \mathrm{M})$ for $24 \mathrm{~h}$. $28 \mathrm{~S}$ was used as a control for efficiency of RNA extraction and transcription. One representative experiment, out of two independent experiments with similar results, is shown. 
A

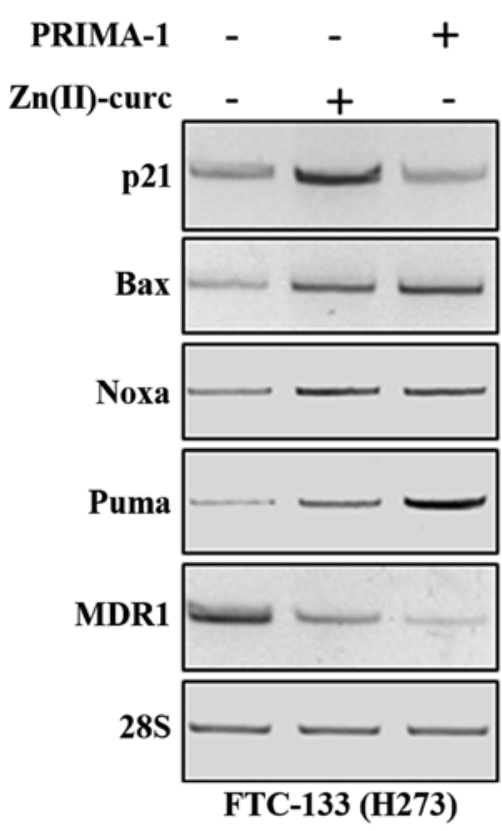

B

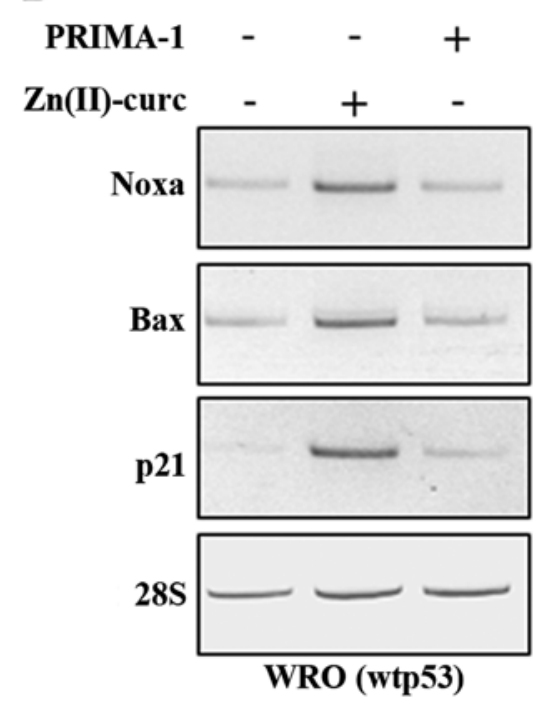

C

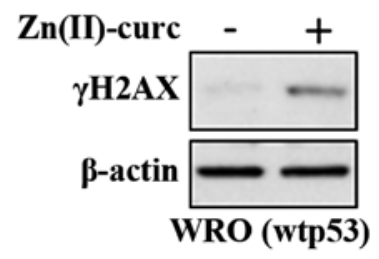

Figure 3. Comparison between Zn(II)-curc and PRIMA-1 on p53 activity. (A) FTC-133 and (B) WRO cells were treated with Zn(II)-curc (80 $\mu$ M) and PRIMA-1 (10 $\mu \mathrm{M})$ for $24 \mathrm{~h}$ before total mRNAs were reverse transcribed for analysis of p53 target genes, using RT-PCR. 28S was used as a control for efficiency of RNA extraction and transcription. One representative experiment, out of two independent experiments with similar results, is shown. (C) WRO cells were treated with $\mathrm{Zn}(\mathrm{II})$-curc $(80 \mu \mathrm{M})$ for $24 \mathrm{~h}$. Equal amount of total cell extracts were subjected to immunoblot analysis with anti- $\gamma \mathrm{H} 2 \mathrm{AX}$ (phopho-Ser139) antibody. Anti- $\beta$-actin was used as protein loading control.

induced expression of the typical p53 target genes already at the lowest dose used, while reduced the expression of mutp53 target MDR1 expression starting from $80 \mu \mathrm{M}$ dose (Fig. 2B). These findings indicate that $\mathrm{Zn}$ (II)-curc produced an imbalance between misfolded/folded p53 proteins in FTC-133 cells that favoured wild-type over mutant p53 functions.

Comparison between Zn(II)-curc and PRIMA-1 on p53 activity. PRIMA-1 is a low molecular weight compound with antitumor activity that has been shown to be more effective in inducing apoptosis in mutp53 cells than in wtp53 cells (33). We then compared the p53 reactivating effect of $\mathrm{Zn}$ (II)-curc with that of PRIMA-1 in both FTC-133 (mutp53) and WRO (wtp53) cells. In vivo transcription of endogenous p53 target genes was examined by employing RT-PCR analysis. The results show that the induction of wtp53 target genes such as Bax, Noxa, Puma and downregulation of the mutp53 target gene $M D R l$ was comparably and efficiently achieved by both treatments, that is, $\mathrm{Zn}$ (II)-curc and PRIMA-1 (Fig. 3A); of note, $\mathrm{Zn}(\mathrm{II})$-curc induced also the wtp53 target, cell cyclerelated $p 21$ gene, unlike PRIMA-1 (Fig. 3A). This latter result is in agreement with PRIMA-1 pro-apoptotic specific function (33). Interestingly, $\mathrm{Zn}$ (II)-curc, differently from PRIMA-1, induced p53 target genes in WRO cells, carrying wtp53 (Fig. 3B), likely due to the DNA intercalating ability of Zn(II)curc compound sensing the DNA damage response (29). Thus, Zn-curc induced H2AX phosphorylation ( $\gamma \mathrm{H} 2 \mathrm{AX}$ ) (Fig. 3C) that is a marker to detect the genotoxic effect of different anticancer agents (34).

Zn(II)-curc modifies prosurvival molecular pathways in FTC-133 cells. P53H273 mutation has been shown to increase epidermal growth factor receptor (EGFR) levels as well as EGFR/PI3K/Akt signaling pathway, facilitating cell proliferation, tumor growth and migration (35). EGFR overexpression is described in several thyroid carcinomas, including follicular thyroid carcinomas (36), and recent evidence implicates EGFR overexpression in advanced thyroid carcinoma progression (37). Therefore, we evaluated the effect of $\mathrm{Zn}$ (II)-curc on EGFR and Akt expression levels in FTC-133 cells. Western blot analyses show that the strong expression of EGFR was markedly reduced by $\mathrm{Zn}$ (II)-curc (Fig. 4A); similarly, Akt phosphorylation was noticeably inhibited by $\mathrm{Zn}$ (II)-curc treatment (Fig. 4B). Moreover, p53 mutants have been shown to regulate E-cadherin expression (38). Downregulation of the E-cadherin cell-cell adhesion molecule is a key event for epithelial to mesenchymal transition (EMT) in tumor progression and it is associated with the development of invasive carcinoma, metastatic dissemination, and poor clinical prognosis (39). We found that $\mathrm{Zn}$ (II)-curc induced re-expression of E-cadherin mRNA levels in FTC-133 cells, that strongly correlated with downregulation of $\mathrm{N}$-cadherin expression, a mesenchymal marker (Fig. 4C), as evidenced by densitometric analysis (Fig. 4C, lower panel) indicative of a reversion of EMT 
A

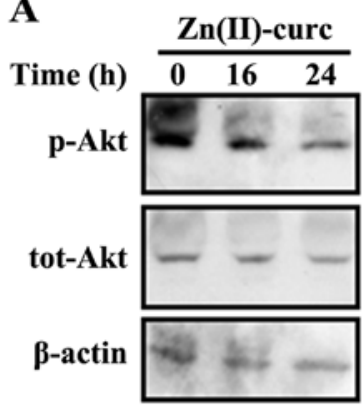

B

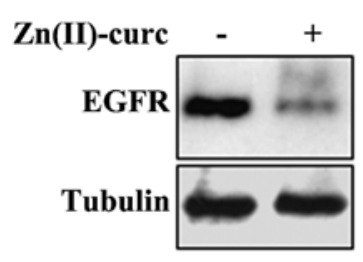

C

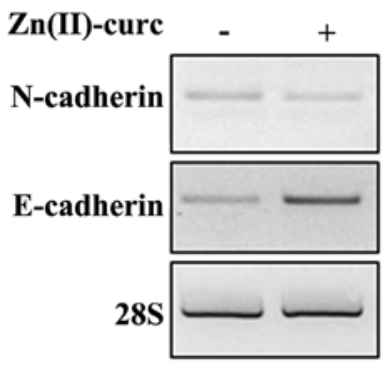

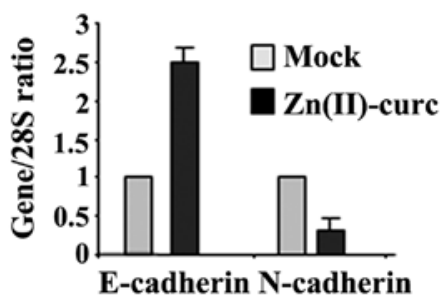

Figure 4. Zn(II)-curc modifies prosurvival molecular pathways in FTC-133 cells. (A) Subconfluent FTC-133 cells were treated with Zn(II)-curc (80 $\mu$ M) for 16 and $24 \mathrm{~h}$. Equal amount of total cell lysates were subjected to immunoblot analysis to detect p-Akt and total-Akt. Anti- $\beta$-actin was used as protein loading control. (B) Cells treated as in (A) for $24 \mathrm{~h}$ were subjected to immunoblot analysis to detect EGFR expression levels. Anti- $\beta$-actin was used as protein loading control. One representative experiment, out of two independent experiments with similar results, is shown. (C) FTC-133 cells were treated with Zn(II)-curc $(80 \mu \mathrm{M})$ for $24 \mathrm{~h}$ before total mRNAs were reverse transcribed for analysis of E-cadherin and N-cadherin gene expression, using RT-PCR. 28S was used as a control for efficiency of RNA extraction and transcription. The lower panel represents densitometric analysis of gene expression, plotted as expression ratio to $28 \mathrm{~S}$. The data represent the mean of two independent experiments \pm SD.
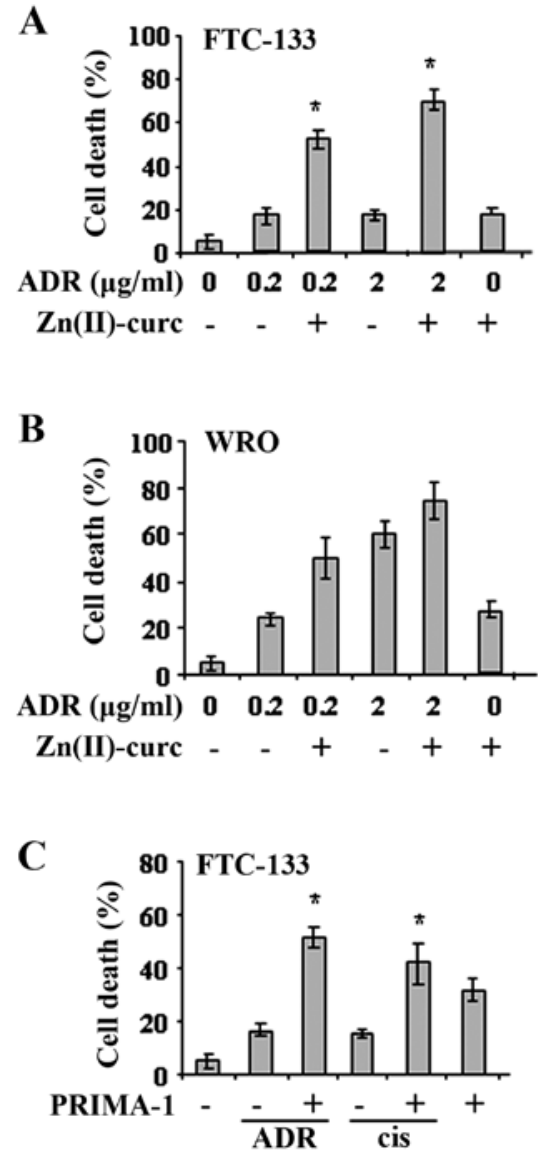
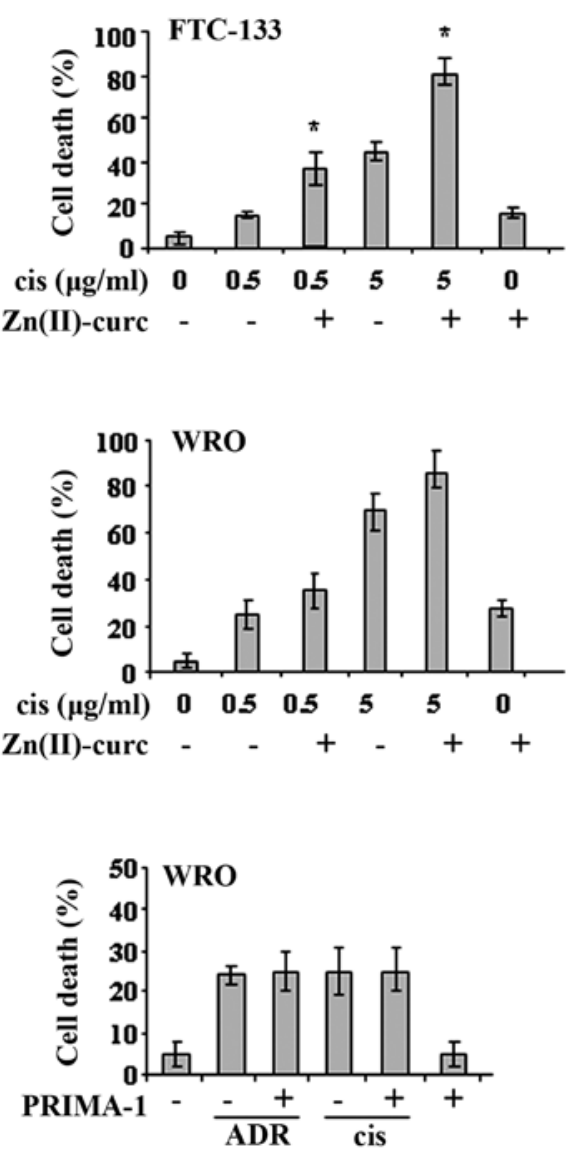

Figure 5. Zn(II)-curc increases the cytotoxic effect of drugs. FTC-133 (A) and WRO(B) cells (2x10 $)$ were plated at subconfluence in 60 -mm Petri dish and the day after treated with $\mathrm{ADR}(0.2$ and $2 \mu \mathrm{g} / \mathrm{ml})$ and cisplatin (cis, 0.5 and $5 \mu \mathrm{g} / \mathrm{ml})$ alone or in combination with $\mathrm{Zn}(\mathrm{II})$-curc (80 $\mu \mathrm{M})$ for $24 \mathrm{~h}$. Cell death was measured by trypan blue exclusion assay and expressed as percentage \pm SD of three independent experiments performed in duplicate. Paired Student's t-test was used for statistical analysis of comparison between the values of drugs alone with that of drugs in combination with $\mathrm{ZnCl}_{2}$ treatments. ${ }^{*} \mathrm{P}<0.01$. (C) FTC-133 and WRO cells were plated as in (A) and (B) and treated with ADR (0.2 $\mu \mathrm{g} / \mathrm{ml})$ and cisplatin (cis, $0.5 \mu \mathrm{g} / \mathrm{ml})$ alone or in combination with PRIMA-1 $(10 \mu \mathrm{M})$ for $24 \mathrm{~h}$. Cell death was measured by trypan blue exclusion assay and expressed as percentage \pm SD. * $<<0.01$. 
phenotype. Altogether, these findings indicate that $\mathrm{Zn}$ (II)-curc could modify prosurvival pathways and counteract mutp53regulated pathways responsible of GOF.

$Z n(I I)$-curc increases the cytotoxic effect of drugs. In order to study the biological effect of Zn(II)-curc we treated FTC-133 and WRO cells with $\mathrm{Zn}$ (II)-curc alone or combination with cisplatin (cis) or adriamycin (ADR) and assessed viability using trypan blue staining. We found that the weak antitumor effect achieved by two different doses $(0.2$ and $2 \mu \mathrm{g} / \mathrm{ml})$ of ADR in FTC-133 cells was significantly increased by $\mathrm{Zn}(\mathrm{II})$-curc co-treatment (Fig. 5A). Similarly, cell death induced by both low $(0.5 \mu \mathrm{g} / \mathrm{ml})$ or high $(5 \mu \mathrm{g} / \mathrm{ml})$ dose of cisplatin was increased by Zn(II)-curc co-treatment, although FTC-133 resulted more sensitive to high dose of cisplatin $(5 \mu \mathrm{g} / \mathrm{ml})$ (Fig. 5A); in agreement with the activation of wtp53 target genes, seen in Fig. 3B, Zn(II)-curc increased the cytotoxic effect of cisplatin and ADR also in this wtp53-carrying cell line (Fig. 5B). In comparison, PRIMA-1 increased chemosensitivity of mutp53 FTC133 cells, while did not affect the response to drugs of wtp53 WRO cells (Fig. 5C). Altogether, these results show that $\mathrm{Zn}$ (II)-curc enhanced the cytotoxic effect of chemotherapeutic drugs in both mutant and wild-type-carrying cancer cells, unlike PRIMA-1 that was effective only in mutp53 cells.

\section{Discussion}

In this study we found that $\mathrm{Zn}$ (II)-curc, a mutant p53 reactivator, was able to downregulate mutp53 in FTC-133 (p53H273) thyroid cancer cells restoring the wtp53 functions and improving cancer cell response to antitumor drugs. In addition, $\mathrm{Zn}(\mathrm{II})$-curc was also able to activate endogenous wtp53 in wtp53 cells WRO.

Several studies have shown that restoration of wild-type p53 activity in vitro (40) and in mice (41-43) induces rapid tumor regression, demonstrating that reconstitution of p53 is indeed sufficient for elimination of tumors even in the presence of other tumor-associated genetic alterations (41-43). Over the past years several strategies have been approached to develop p53-targeted drugs, and in particular to develop small molecule compounds that activate wtp53 and restore wtp53 function of mutant p53 proteins (44), as abrogation of mutp53 has been shown to reduce tumor malignancy (45). Thus, some mutp53 proteins such as p53H273 have been shown to acquire gain of function (GOF) that actively contributes to cancer development and progression and chemoresistance (11). At the molecular levels GOF effects were shown to be linked to the ability of mutp53 to increase the expression of several genes including MDR1 (multi-drug resistance gp180 protein). Moreover, p53H273 mutation has been shown to increase epidermal growth factor receptor (EGFR) levels as well as EGFR/PI3K/ Akt signaling pathway, facilitating cell proliferation and tumor growth (35). Here, we found that $\mathrm{Zn}$ (II)-curc was able to downregulate mutp53 protein levels. In agreement with the loss of mutant p53 protein, $\mathrm{Zn}$ (II)-curc reduced EGFR expression and Akt phosphorylation as well as induced reversion of EMT, suggesting modulation of mutp53-dependent gain of function pathways. The reversion of EMT by Zn(II)-curc is particularly intriguing because EMT induction has been shown to promote cancer stem cell (CSC) traits in the thyroid cancer cells, with the potential to induce cancer stem cell generation and tumor progression in thyroid cancers (46). The effect of $\mathrm{Zn}$ (II)-curc on mutp53 downregulation depended in part on induction of autophagy, as previously reported (28). Autophagy plays a dual role during cancer development, progression and treatment, mainly depending on the type and stage of the tumor. The induction of autophagy by $\mathrm{Zn}(\mathrm{II})$-curc is interesting in light of studies showing that, in thyroid cancer, autophagy activation increases chemosensitivity, enhances the iodine uptake ability, and reverses the dedifferentiation phenotype (47). Parallel to mutp53 downregulation, $\mathrm{Zn}$ (II)-curc reactivated the wild-type p53 functions, likely through the imbalance of misfolded/ folded protein conformation. These molecular changes correlated with improvement, at biological level, of the cytotoxic effect of chemotherapeutic drugs, increasing thyroid cancer cell death.

The presence of p53 mutations is a late event in thyroid cancer progression. The mutations of $\mathrm{p} 53$ or increased expression of $\mathrm{p} 53$ protein is associated with the progression from differentiated to anaplastic carcinoma and is implicated in chemoresistance (17). Recently, some attention has been focused on Zinc compounds for p53 reactivation (48). In this regard, compounds that can both promote mutp53 degradation and reactivation of wtp53 functions may have therapeutic advantages, as is the case with $\mathrm{Zn}(\mathrm{II})$-curc. To strengthen the role of $\mathrm{Zn}$ (II)-curc as mutp53 reactivator, the effect of $\mathrm{Zn}$ (II)curc was compared to that of PRIMA-1, a low molecular weight compound that reactivates mutp53 and that has been shown to be more effective in inducing apoptosis in mutp53 cells than in wtp53 cells (33). Such compound has been shown to induce cell death in thyroid cancer cells carrying p53 mutations and particularly p53H273 mutation (18). Of note, $\mathrm{Zn}$ (II)-curc restored wtp53 activity similarly to PRIMA-1 in FTC-133 cells and increased the cytotoxic effect of drugs. In addition, $\mathrm{Zn}$ (II)-curc was able to activate endogenous wtp53 in WRO cells, unlike PRIMA-1 that did not have such effect on wtp53 protein.

The classic treatment of thyroid cancer is total thyroidectomy, followed by, in some cases, radioiodine treatment. Surgically inoperable and radioiodine-refractory differentiated thyroid cancers, poorly differentiated thyroid cancer, and anaplastic thyroid cancer are currently the major causes of deaths related to thyroid cancer and do not have effective treatments (3-6). In this regard, molecular-based management strategies for thyroid nodules and thyroid cancer are a novel and intense area of development in molecular thyroid-cancer medicine (49). In line with this strategy, the present findings, although preliminary due to the small number of cell lines analyzed, suggest that $\mathrm{Zn}$ (II)-curc may be a useful adjuvant in the treatment of thyroid cancer cells carrying both both mutant and wild-type p53 proteins. Thus, although well differentiated thyroid carcinomas are efficiently cured by surgery and radioiodine, undifferentiated thyroid carcinomas (10-20\% of total) are very resistant to chemotherapy and the restoration of chemosensitivity, through p53 reactivation for instance, may be an efficient antitumor strategy. The use of Zn(II)-curc in clinical practice is strengthen also by our previous studies showing other biological effects of zinc supplementation such as restoration of immune response (50) and inhibition of hypoxia-induced molecular pathways $(51,52)$. This is 
particularly relevant because hypoxia-inducible factor is often overexpressed in thyroid cancer contributing to chemoresistance and tumor progression (53). In earlier observations $\mathrm{Zn}$ (II) has been found to have cytotoxic effect on thyroid cancer cell lines (55), although the molecular mechanisms were not fully elucidated. Here we propose the use of $\mathrm{Zn}(\mathrm{II})$-curc as p53 (re) activator in therapeutic regimens of thyroid cancers, carrying both mutant and wtp53, that will be worth further testing for translational purpose in clinical practice.

\section{Acknowledgements}

This study was supported by Grant from the Italian Association for Cancer Research (AIRC, IG11377 to G.D.). The authors wish to thank Dr Fabiola Moretti and Dr Oreste Segatto for sharing reagents. We also thank Dr Maria Pia Gentileschi for technical assistance.

\section{References}

1. Sipos JA and Mazzaferri EL: Thyroid cancer epidemiology and prognostic variables. Clin Oncol (R Coll Radiol) 22: 395-404, 2010.

2. Kim DS, McCabe CJ, Buchanan MA and Watkinson JC: Oncogenes in thyroid cancer. Clin Otolaryngol Allied Sci 28: 386-395, 2003

3. Urciuoli P, Ghinassi S, Iavarone C,Peparini N,D'Orazi V, Gabatel R, Pichelli D, Iachetta RP and Custureri F: Thyroid anaplastic tumor: Our experience. Chir Ital 55: 835-840, 2003 (In Italian).

4. Pulcrano M, Boukheris H, Talbot M, Caillou B, Dupuy C, Virion A, De Vathaire F and Schlumberger M: Poorly differentiated follicular thyroid carcinoma: Prognostic factors and relevance of histological classification. Thyroid 17: 639-646, 2007.

5. Rajhbeharrysingh U, Taylor M and Milas M: Medical therapy for advanced forms of thyroid cancer. Surg Clin North Am 94: 541-571, 2014

6. Nguyen QT, Lee EJ, Huang MG, Park YI, Khullar A and Plodkowski RA: Diagnosis and treatment of patients with thyroid cancer. Am Health Drug Benefits 8: 30-40, 2015.

7. Hainaut $P$ and Hollstein M: p53 and human cancer: The first ten thousand mutations. Adv Cancer Res 77: 81-137, 2000.

8. Beckerman R and Prives C: Transcriptional regulation by $\mathrm{p} 53$ Cold Spring Harb Perspect Biol 2: a000935, 2010.

9. Tchelebi L, Ashamalla $\mathrm{H}$ and Graves PR: Mutant p53 and the response to chemotherapy and radiation. Subcell Biochem 85 133-159, 2014.

10. Milner J and Medcalf EA: Cotranslation of activated mutant 553 with wild type drives the wild-type p53 protein into the mutant conformation. Cell 65: 765-774, 1991.

11. Blandino G, Levine AJ and Oren M: Mutant p53 gain of function: Differential effects of different p53 mutants on resistance of cultured cells to chemotherapy. Oncogene 18: 477-485, 1999.

12. Gurtner A, Starace G, Norelli G, Piaggio G, Sacchi A and Bossi G: Mutant p53-induced up-regulation of mitogen-activated protein kinase kinase 3 contributes to gain of function. J Biol Chem 285: 14160-14169, 2010

13. Ubertini V, Norelli G, D'Arcangelo D, Gurtner A, Cesareo E, Baldari S, Gentileschi MP, Piaggio G, Nisticò P, Soddu S, et al: Mutant p53 gains new function in promoting inflammatory signals by repression of the secreted interleukin-1 receptor antagonist. Oncogene 34: 2493-2504, 2015.

14. Lang GA, Iwakuma T, Suh YA, Liu G, Rao VA, Parant JM, Valentin-Vega YA, Terzian T, Caldwell LC, Strong LC, et al: Gain of function of a p53 hot spot mutation in a mouse model of Li-Fraumeni syndrome. Cell 119: 861-872, 2004.

15. Olive KP, Tuveson DA, Ruhe ZC, Yin B, Willis NA, Bronson RT, Crowley D and Jacks T: Mutant p53 gain of function in two mouse models of Li-Fraumeni syndrome. Cell 119: 847-860, 2004.

16. Donghi R, Longoni A, Pilotti S, Michieli P, Della Porta G and Pierotti MA: Gene p53 mutations are restricted to poorly differentiated and undifferentiated carcinomas of the thyroid gland. J Clin Invest 91: 1753-1760, 1993.
17. Parameswaran R, Brooks S and Sadler GP: Molecular pathogenesis of follicular cell derived thyroid cancers. Int J Surg 8: 186-193, 2010.

18. Messina RL, Sanfilippo M, Vella V, Pandini G, Vigneri P, Nicolosi ML, Gianì F, Vigneri R and Frasca F: Reactivation of p53 mutants by prima-1 [corrected] in thyroid cancer cells. Int J Cancer 130: 2259-2270, 2012.

19. Zawacka-Pankau J and Selivanova G: Pharmacological reactivation of p53 as a strategy to treat cancer. J Intern Med 277: 248-259, 2015.

20. Puca R, Nardinocchi L, Gal H, Rechavi G, Amariglio N, Domany E, Notterman DA, Scarsella M, Leonetti C, Sacchi A, et al: Reversible dysfunction of wild-type p53 following homeodomain-interacting protein kinase-2 knockdown. Cancer Res 68: 3707-3714, 2008.

21. Puca R, Nardinocchi L, Bossi G, Sacchi A, Rechavi G, Givol D and D'Orazi G: Restoring wtp53 activity in HIPK2 depleted MCF7 cells by modulating metallothionein and zinc. Exp Cell Res 315: 67-75, 2009.

22. Puca R, Nardinocchi L, Porru M, Simon AJ, Rechavi G, Leonetti C, Givol D and D'Orazi G: Restoring p53 active conformation by zinc increases the response of mutant p53 tumor cells to anticancer drugs. Cell Cycle 10: 1679-1689, 2011.

23. Cho Y, Gorina S, Jeffrey PD and Pavletich NP: Crystal structure of a p53 tumor suppressor-DNA complex: Understanding tumorigenic mutations. Science 265: 346-355, 1994.

24. Loh SN: The missing zinc: p53 misfolding and cancer. Metallomics 2: 442-449, 2010.

25. D'Orazi G and Givol D: p53 reactivation: The link to zinc. Cell Cycle 11: 2581-2582, 2012.

26. Blanden AR, Yu X, Wolfe AJ, Gilleran JA, Augeri DJ, O'Dell RS, Olson EC, Kimball SD, Emge TJ, Movileanu L, et al: Synthetic metallochaperone $\mathrm{ZMC1}$ rescues mutant $\mathrm{p} 53$ conformation by transporting zinc into cells as an ionophore. Mol Pharmacol 87: 825-831, 2015.

27. Garufi A, Trisciuoglio D, Porru M, Leonetti C, Stoppacciaro A, D'Orazi V, Avantaggiati M, Crispini A, Pucci D and D'Orazi G: A fluorescent curcumin-based $\mathrm{Zn}$ (II)-complex reactivates mutant (R175H and R273H) p53 in cancer cells. J Exp Clin Cancer Res 32: 72, 2013.

28. Garufi A,Pucci D, D'Orazi V,Cirone M, Bossi G, Avantaggiati ML and D'Orazi G: Degradation of mutant $\mathrm{p} 53 \mathrm{H} 175$ protein by $\mathrm{Zn}(\mathrm{II})$ through autophagy. Cell Death Dis 5: e1271, 2014.

29. Pucci D, Bellini T, Crispini A, D'Agnano I, Liguori PF, GarciaOrduña P, Pirillo S, Valentini A and Zanchetta G: DNA binding and cy totoxicity of fluorescent curcumin-based $\mathrm{Zn}$ (II) complexes. Med Chem Comm 3: 462-468, 2012.

30. Pucci D, Crispini A, Sanz Mendiguchía B, Pirillo S, Ghedini M, Morelli S and De Bartolo L: Improving the bioactivity of $\mathrm{Zn}(\mathrm{II})-$ curcumin based complexes. Dalton Trans 42: 9679-9687, 2013.

31. Garufi A, D'Orazi V, Arbiser JL and D'Orazi G: Gentian violet induces wtp53 transactivation in cancer cells. Int J Oncol 44: 1084-1090, 2014

32. Barth S, Glick D and Macleod KF: Autophagy: Assays and artifacts. J Pathol 221: 117-124, 2010.

33. Bykov VJ, Issaeva N, Shilov A, Hultcrantz M, Pugacheva E, Chumakov P, Bergman J, Wiman KG and Selivanova G: Restoration of the tumor suppressor function to mutant $\mathrm{p} 53$ by a low-molecular-weight compound. Nat Med 8: 282-288, 2002.

34. Podhorecka M, Skladanowski A and Bozko P: H2AX phosphorylation: its role in DNA damage response and cancer therapy. J Nucleic Acids 2010: 920161, 2010.

35. Wang W, Cheng B, Miao L, Mei Y and Wu M: Mutant p53-R273H gains new function in sustained activation of EGFR signaling via suppressing miR-27a expression. Cell Death Dis 4: e574, 2013.

36. Liu Z, Hou P, Ji M, Guan H, Studeman K, Jensen K, Vasko V, El-Naggar AK and Xing M: Highly prevalent genetic alterations in receptor tyrosine kinases and phosphatidylinositol 3-kinase/ akt and mitogen-activated protein kinase pathways in anaplastic and follicular thyroid cancers. J Clin Endocrinol Metab 93: 3106-3116, 2008

37. Landriscina M, Pannone G, Piscazzi A, Toti P, Fabiano A Tortorella S, Occhini R, Ambrosi A, Bufo P and Cignarelli M: Epidermal growth factor receptor 1 expression is upregulated in undifferentiated thyroid carcinomas in humans. Thyroid 21: 1227-1234, 2011

38. Roger L, Jullien L, Gire V and Roux P: Gain of oncogenic function of p53 mutants regulates E-cadherin expression uncoupled from cell invasion in colon cancer cells. J Cell Sci 123: 1295-1305, 2010 . 
39. Perl AK, Wilgenbus P, Dahl U, Semb H and Christofori G: A causal role for E-cadherin in the transition from adenoma to carcinoma. Nature 392: 190-193, 1998

40. D'Orazi G, Marchetti A, Crescenzi M, Coen S, Sacchi A and Soddu S: Exogenous wt-p53 protein is active in transformed cells but not in their non-transformed counterparts: Implications for cancer gene therapy without tumor targeting. J Gene Med 2: $11-21,2000$.

41. Martins CP, Brown-Swigart L and Evan GI: Modeling the therapeutic efficacy of p53 restoration in tumors. Cell 127: 1323-1334, 2006.

42. Ventura A, Kirsch DG, McLaughlin ME, Tuveson DA, Grimm J, Lintault L, Newman J, Reczek EE, Weissleder R and Jacks T: Restoration of $\mathrm{p} 53$ function leads to tumour regression in vivo. Nature 445: 661-665, 2007

43. Xue W, Zender L, Miething C, Dickins RA, Hernando E, Krizhanovsky V, Cordon-Cardo C and Lowe SW: Senescence and tumour clearance is triggered by $\mathrm{p} 53$ restoration in murine liver carcinomas. Nature 445: 656-660, 2007.

44. Yu X, Narayanan S, Vazquez A and Carpizo DR: Small molecule compounds targeting the p53 pathway: Are we finally making progress? Apoptosis 19: 1055-1068, 2014.

45. Bossi G, Lapi E, Strano S, Rinaldo C, Blandino G and Sacchi A Mutant p53 gain of function: Reduction of tumor malignancy of human cancer cell lines through abrogation of mutant p53 expression. Oncogene 25: 304-309, 2006.

46. Lan L, Luo Y, Cui D, Shi B-Y, Deng W, Huo L-L, Chen H-L, Zhang G-Y and Deng L-L: Epithelial-mesenchymal transition triggers cancer stem cell generation in human thyroid cancer cells. Int J Oncol 43: 113-120, 2013.
47. Yi H, Long B, Ye X, Zhang L, Liu X and Zhang C: Autophagy: A potential target for thyroid cancer therapy (Review). Mol Clin Oncol 2: 661-665, 2014

48. Khoo KH, Verma CS and Lane DP: Drugging the p53 pathway: Understanding the route to clinical efficacy. Nat Rev Drug Discov 13: 217-236, 2014.

49. Xing M, Haugen BR and Schlumberger M: Progress in molecular-based management of differentiated thyroid cancer. Lancet 381: 1058-1069, 2013.

50. Cirone M, Garufi A, Di Renzo L, Granato M, Faggioni A and D'Orazi G: Zinc supplementation is required for the cytotoxic and immunogenic effects of chemotherapy in chemoresistant p53-functionally deficient cells. OncoImmunology 2: e26198, 2013.

51. Nardinocchi L, Puca R, Sacchi A, Rechavi G, Givol D and D'Orazi G: Targeting hypoxia in cancer cells by restoring homeodomain interacting protein-kinase 2 and p53 activity and suppressing HIF-1alpha. PLoS One 4: e6819, 2009.

52. Nardinocchi L, Pantisano V, Puca R, Porru M, Aiello A, Grasselli A, Leonetti C, Safran M, Rechavi G, Givol D, et al: Zinc downregulates HIF- $1 \alpha$ and inhibits its activity in tumor cells in vitro and in vivo. PLoS One 5: e15048, 2010.

53. Burrows N, Babur M, Resch J, Williams KJ and Brabant G: Hypoxia-inducible factor in thyroid carcinoma. J Thyroid Res 2011: 762905, 2011.

54. Iitaka M, Kakinuma S, Fujimaki S, Oosuga I, Fujita T, Yamanaka K, Wada S and Katayama S: Induction of apoptosis and necrosis by zinc in human thyroid cancer cell lines. J Endocrinol 169: 417-424, 2001. 